Article

\title{
Preparation and Properties of Capric-Myristic Acid/Expanded Graphite Composite Phase Change Materials for Latent Heat Thermal Energy Storage
}

\author{
Dongyi Zhou ${ }^{1,2,3}$, Jiawei Yuan ${ }^{2}$, Yuhong Zhou ${ }^{2}$ and Yicai Liu ${ }^{1, *}$ \\ 1 School of Energy Science and Engineering, Central South University, Changsha 410083, China; \\ hnsyuzhou@hnsyu.edu.cn \\ 2 School of Mechanical and Energy Engineering, Shaoyang University, Shaoyang 422000, China; \\ y951723@163.com (J.Y.); yuhong0093@163.com (Y.Z.) \\ 3 Key Laboratory of Hunan Province for Efficient Power System and Intelligent Manufacturing, Shaoyang \\ University, Shaoyang 422000, China \\ * Correspondence: lyc0300@163.com; Tel.: +86-0731-8887-6111
}

Received: 9 April 2020; Accepted: 6 May 2020; Published: 14 May 2020

\begin{abstract}
A novel composite phase change material (CPCM), capric-myristic acid/expanded graphite (CA-MA/EG) CPCM, was prepared by absorbing liquid CA-MA (as the phase change material (PCM)) into EG (as the substrate material) for heat storage in the backfill materials of soil-source heat pump systems. The thermal characteristics and microstructure of the novel CPCM were analyzed using differential scanning calorimetry (DSC) and scanning electronic microscopy (SEM). The thermal conductivities of CA-MA/EG CPCM were surveyed. The thermal stability of the CA-MA/EG was analyzed using thermogravimetric analysis (TGA) and thermal cycle tests. The results showed that the optimal mass content of CA-MA in CPCM was approximately $92.4 \%$ and the CA-MA was uniformly distributed in the vesicular structure of EG; the CA-MA/EG CPCM had an appropriate phase change temperature $\left(T_{m}: 19.78^{\circ} \mathrm{C}, T_{f}: 18.85^{\circ} \mathrm{C}\right)$, high latent heat $\left(H_{m}: 137.3 \mathrm{~J} / \mathrm{g}, H_{f}: 139.9 \mathrm{~J} / \mathrm{g}\right)$, and excellent thermostability and thermal reliability. The thermal conductivity of the CPCM was remarkably enhanced after adding EG. Therefore, the CPCMs demonstrated outstanding thermal performance and can be utilized in low-temperature latent heat thermal energy storage (LHTES) systems, such as soil-source heat pump systems.
\end{abstract}

Keywords: fatty acids; expanded graphite; thermal properties; thermal energy storage; phase change materials

\section{Introduction}

Phase change materials (PCMs) can be utilized to store thermal energy temporarily and release it when necessary, which can alleviate the contradiction of energy supply-demand and energy saving. Thermal energy storage by virtue of latent heat is a powerful method to enhance energy efficiency [1]. To date, PCMs for thermal energy storage have been widely employed for solar energy utilization [2], building energy savings [3], industrial waste heat recovery [4], and air conditioning condensation heat recovery systems [5].

In accordance with the chemical composition, PCMs can be classified as organic phase change materials [6], inorganic phase change materials [7], and composite phase change materials [8]. Organic phase change materials are mainly divided into esters, sugar alcohols, paraffins [9], and aliphatic acids [10]. Fatty acid PCMs have been generally utilized for their positive characteristics, including large latent heat of phase change, no supercooling, non-toxicity, and their low price [11]. When aliphatic acids are utilized as PCMs, the choice of the phase transition temperature is very flexible; not only can 
it be used alone, but binary or multi-component mixed fatty acids can be made by the eutectic effect, and the composition can be changed to achieve the purpose of flexibly changing the phase change temperature [12].

In the previous literature, studies on fatty acids mainly focused on binary and ternary systems $[13,14]$. Certain thermal properties of binary, ternary, or multicomponent aliphatic acid eutectic mixtures, and other organic PCMs have been reported [15-19]. These research results showed that the eutectic mixtures of aliphatic acids have many appropriate characteristics for their use as thermal energy storage materials.

Although fatty acids have many advantages, they still have the negative characteristics of poor thermal conductivity and easy leakage of pure phase change materials. To resolve this problem, high thermal conductivity materials can be added into fatty acid PCMs to prepare composite phase change materials. Not only can composite phase change materials be improved in terms of thermal conductivity but they can also be made into stable PCMs, which are not as likely to leak [20,21]. The commonly used base materials for preparing shaped phase change materials include expanded graphite [22,23], expanded perlite [24], and diatomite [25]. Common preparation methods include the microcapsule method [26], melt-gel method [27], and physical adsorption method.

Fu et al. [28] prepared stearic acid/diatomite composite stable PCMs by direct impregnation using vacuum treatment. The results show that the stearic acid/diatomite composite phase change materials (CPCMs) melt and freeze at $52.3^{\circ} \mathrm{C}$ and $48.4^{\circ} \mathrm{C}$, respectively, with a latent heat of $57.1 \mathrm{~J} / \mathrm{g}$, which has the potential for practical applications with good thermal stability. He et al. [29] prepared a lauric acid-myristic acid/expanded graphite (LA-MA/EG) CPCM, determined the appropriate sintering process and absorption quantity of EG, and mixed the LA-MA/EG composite material into cement mortar to prepare a PCM-based mortar. The results showed that PCM mortar had a good temperature control effect, with the effective calorific value reduced, the temperature peak time delayed, and a larger cooling range.

Wei et al. [30] prepared a novel decanoic acid-nutmeg-stearic acid/modified expanded vermiculite composite (CA-MA-SA/AEVC) phase change material. The effects indicated that the thermal conductivity of CA-MA-SA/AEVC was significantly enhanced by the introduction of carbon. The melting and freezing points were $22.92{ }^{\circ} \mathrm{C}$ and $21.03{ }^{\circ} \mathrm{C}$, respectively, but the corresponding latent heats were $86.4 \mathrm{~J} / \mathrm{g}$ and $80.4 \mathrm{~J} / \mathrm{g}$, respectively. Many studies [31-33] have shown that the addition of graphite not only plays a supporting role in preventing leakage of molten PCM but also greatly improves the thermal conductivity of the composite phase change materials. The heat performances of some PCMs and composite phase change materials (CPCMs) are shown in Table 1.

Table 1. Heat performances of some phase change materials (PCMs) and composite phase change materials (CPCMs). Capric acid (CA), myristic acid (MA), expanded graphite (EG), stearic acid (SA), lauric acid (LA), palmitic acid (PA), octadecane (OC).

\begin{tabular}{|c|c|c|c|c|c|}
\hline \multirow{2}{*}{ PCMs/CPCMs } & \multicolumn{2}{|c|}{ Melting } & \multicolumn{2}{|c|}{ Freezing } & \multirow{2}{*}{ References } \\
\hline & Temperature $\left({ }^{\circ} \mathrm{C}\right)$ & Latent Heat (J/g) & Temperature $\left({ }^{\circ} \mathrm{C}\right)$ & Latent Heat (J/g) & \\
\hline PA-SA & 54.81 & 187.0 & 54.06 & 179.7 & \multirow{2}{*}{ [34] } \\
\hline PA-SA/EG & 55.18 & 176.2 & 54.91 & 175.6 & \\
\hline MA-PA-SA & 41.72 & 163.5 & 42.38 & 159.8 & \multirow{2}{*}{ [35] } \\
\hline MA-PA-SA/EG & 41.64 & 153.5 & 42.99 & 151.4 & \\
\hline LA-MA-SA & 29.29 & 140.9 & 28.38 & 137.2 & \multirow{2}{*}{ [36] } \\
\hline LA-MA-SA/EG & 29.05 & 137.1 & 29.38 & 131.3 & \\
\hline CA-PA-SA & 18.90 & 147.2 & 16.73 & 142.3 & \multirow{2}{*}{ [37] } \\
\hline CA-PA-SA/EG & 21.33 & 131.7 & 19.01 & 127.2 & \\
\hline LA-SA & 35.54 & 159.9 & 34.36 & / & \multirow{2}{*}{ [38] } \\
\hline LA-SA/EG & 35.69 & 143.4 & 34.28 & / & \\
\hline LA-MA-PA & 31.41 & 145.8 & / & / & \multirow{2}{*}{ [39] } \\
\hline LA-MA-PA/EG & 30.94 & 135.9 & / & / & \\
\hline OC-PA & 28.78 & 181.6 & / & l & \multirow{2}{*}{ [40] } \\
\hline OC-PA/EG & 29.18 & 160.7 & / & / & \\
\hline CA-MA & 19.45 & 150.9 & 18.34 & 149.2 & \multirow{2}{*}{ This study } \\
\hline CA-MA/EG & 19.78 & 137.3 & 18.85 & 139.8 & \\
\hline
\end{tabular}


Most of the existing studies only focused on mono- or poly-fatty acid eutectic mixtures in the temperature range of $30-60{ }^{\circ} \mathrm{C}$, which are mostly used in energy-efficient buildings and solar energy utilization. To the best of our knowledge, few studies focused on the backfill well energy storage materials for a buried pipe heat-exchanger of a soil-source heat pump with a phase transition temperature of around $20^{\circ} \mathrm{C}$. The key to stable and efficient operation of the soil-source heat pump system is the heat transfer between the underground heat exchanger and the soil. The temperature of shallow soil is essentially constant below $15 \mathrm{~m}$. For example, it is $19^{\circ} \mathrm{C}$ in Shanghai, China [41].

The temperature of the soil around the buried pipe will vary when the system runs for a long time, resulting in a decrease in the speed of the system. Therefore, the capability of the backfill material around the buried tube heat exchanger is especially crucial. We prepared CA-MA PCMs with a phase transition temperature of $19.4^{\circ} \mathrm{C}$ and studied the thermal performance. The latent heat of phase change reached $150.9 \mathrm{~J} / \mathrm{g}$, which is an appropriate PCM for the backfilling well of a soil-source heat pump buried tube heat exchanger, but the heat transfer performance of the composite PCMs was not studied and improved [42].

This study concentrated on novel latent heat thermal energy storage PCM for the backfill materials of soil-source heat pump systems. A capric-myristic acid ternary eutectic mixture (CA-MA) was prepared with melting and freezing temperatures of $19.4{ }^{\circ} \mathrm{C}$ and $18.3^{\circ} \mathrm{C}$, respectively, and then the CA-MA/EG composite PCM was prepared for soil-source heat pump systems. The thermal characteristics, microstructure, thermal conductivity, thermal reliability, and thermal stability of the composite PCM were studied carefully.

\section{Materials and Methods}

\subsection{Materials}

Capric acid (CA, pure $\geq 98.5 \%$ ) and myristic acid (MA, pure $\geq 98.0 \%$ ) were supplied by Shanghai Zhunyun Chemical Co, Ltd., Shanghai, China. Expansible graphite (Carbon content $>99 \%$, expansion coefficient: $100 \mathrm{~mL} / \mathrm{g}$, 350 meshes) was purchased from Qingdao hengrunda graphite products Co, Ltd., Qingdao, China.

\subsection{Preparation of Capric-Myristic Acid Binary Eutectic Solution}

The CA and MA were weighed according to the mass ratio of 72:28 and then mixed in a beaker. The admixture was heated with separated water in a magnetic agitator to $50^{\circ} \mathrm{C}$ and stirred for $1 \mathrm{~h}$ to obtain the CA-MA phase change material.

\subsection{Preparation of $C A-M A / E G C P C M s$}

Expanded graphite was obtained by heating the dried expandable graphite in a porcelain crucible for $40 \mathrm{~s}$ in a $900{ }^{\circ} \mathrm{C}$ muffle furnace. A quantity of prepared expanded graphite and the CA-MA binary eutectic were fully mixed in a beaker, and then the beaker was placed into an $80^{\circ} \mathrm{C}$ constant temperature water bath for $48 \mathrm{~h}$. After the CA-MA binary eutectic solution melted, the mixture was stirred every $2 \mathrm{~h}$ to ensure that the eutectic solution was fully absorbed by the EG. Then, the prepared CA-MA/EG CPCMs were cooled to ambient temperature for the next characterization.

\subsection{Experiment of Maximum Mass Absorption Ratio of the CA-MA in the CA-MA/EG CPCMs}

About $5 \mathrm{~g}$ of CA-MA/EG composite PCMs with six ratios were weighed using an electronic balance and placed in the beaker. This was placed into a $50{ }^{\circ} \mathrm{C}$ incubator to keep it warm for $48 \mathrm{~h}$ and shaken every $2 \mathrm{~h}$. Six kinds of CA-MA/EG composite phase change material samples were prepared after adsorption with a sufficient mixture of CA-MA and EG. The mass ratios of CA-MA were $90 \%$, $91 \%, 92 \%, 93 \%, 94 \%$, and $95 \%$, respectively. About $0.5 \mathrm{~g}$ of CA-MA/EG composite phase change material was weighed for each sample and placed on filter paper. This was placed into the incubator 
at $50{ }^{\circ} \mathrm{C}$ and kept warm for $30 \mathrm{~min}$. This was then removed and we observed the adsorbed CA-MA mixture solution on the filter paper.

\subsection{Thermal Conductivities Test of CA-MA/EG CPCMs}

Five groups of different quality CPCMs were heated to $50^{\circ} \mathrm{C}$, and then were placed in a cake model with a diameter of $3 \mathrm{~cm}$, respectively. The cake samples with smooth surfaces and different densities were prepared by pressing, grinding, and cooling. Due to the different quality and compression strengths of the samples, the packing densities of the samples were different. The thermal conductivities of CA-MA/EG CPCMs were surveyed by a Hot Disk thermal constants analyzer (TPS2500, Hot Disk AB Company Sweden, Gothenburg, Sweden) at ambient temperature with an accuracy of $\pm 3 \%$.

\subsection{Characterization}

The phase change temperature (melting and freezing temperatures) and latent heat (melting and freezing latent heat) of the CA-MA and the CA-MA/EG before and after thermal cycling were determined by differential scanning calorimetry (DSC, TA Q20, TA Instruments, New Castle, USA), adjusted with an indium standard at a temperature range of $0-60{ }^{\circ} \mathrm{C}$. The heating/cooling rate of DSC measurement was $5{ }^{\circ} \mathrm{C} / \mathrm{min}$, and the samples were cooled by liquid nitrogen. The measurement of the same sample DSC measurements was performed three times. The accuracy of the phase change temperature was $\pm 0.05^{\circ} \mathrm{C}$ and $\pm 0.1 \%$ for latent heats. The extrapolated onset temperatures on the DSC curves were the transformation temperature of the PCMs.

The thermal stability of the CA-MA/EG was analyzed by the thermogravimetric analysis technique (TGA, TA Q50, TA Instruments, New Castle, USA) at a temperature range of $25-500{ }^{\circ} \mathrm{C}$ under a nitrogen gas atmosphere at a heating rate of $10^{\circ} \mathrm{C} / \mathrm{min}$ with an accuracy of $\pm 0.2 \%$. We used a scanning electronic microscope (SEM, Phenom LE, Phenom-World, Eindhoven, the Netherlands) to inspect the microscopic structure of the EG and CA-MA/EG composite phase change materials.

The effect of the thermal cycles on the thermal properties was investigated by heating the CA-MA eutectic mixtures from a solid to a liquid state and then cooling from a liquid to a solid state using a High Low Temperature Test Box (XF/GDW, Shanghai Xiangfeng test instrument and equipment Co. LTD., Shanghai, China). A test tube with a quantity of CA-MA/EG composite PCMs samples was heated in the test box until the center temperature of the samples reached $30^{\circ} \mathrm{C}$, indicating that the CA-MA had completely melted. Then, the samples were cooled in the test box until the center temperature of samples reached $10{ }^{\circ} \mathrm{C}$, indicating that the CA-MA had completely frozen. The above heating/cooling cycle process was stopped until the thermal cycles reached 500 and 1000 times. The heating/cooling rate of the High Low Temperature Test Box was $5{ }^{\circ} \mathrm{C} / \mathrm{min}$, and the samples were cooled by a mechanical compression refrigeration system. We used DSC to measure the changes in performance.

\section{Results and Discussion}

\subsection{Maximum Mass Absorption Ratio of the $C A-M A$ in the $C A-M A / E G C P C M s$}

The main factors influencing the performance of PCMs are the phase change temperature, latent heat, and thermal conductivity. When selecting PCMs, an appropriate phase transition temperature should be selected and PCMs with higher latent heat and thermal conductivity should be selected at this temperature. Generally, the higher the mass of fatty acids in composite PCMs, the larger the phase change latent heat value of the composite materials. In order to obtain more CA-MA per unit mass without leakage, the ratio of CA-MA to EG must be measured.

The experimental results are shown in Figure 1. As shown in Figure 1a, for samples with $94 \%$ and $95 \%$ mass ratios, the filter paper around the material was completely soaked with obvious leakage, which did not meet the requirements of the optimal ratio. For samples with mass ratios of $90 \%$ and $91 \%$, the samples were too dry, indicating that the content of the CA-MA/EG eutectic mixture was too 
small; this would lead to an excessively low latent heat of phase transition, which did not meet the requirements of the phase change materials. The leakage of samples with mass ratios of $92 \%$ and $93 \%$ was not obvious. After brushing the samples (see Figure 1b), the sample with a mass ratio of $92 \%$ had no leakage on the filter paper, while the sample with a mass ratio of $93 \%$ had some micro-leakage on the filter paper, indicating that the optimal quality was between $92 \%$ and $93 \%$.

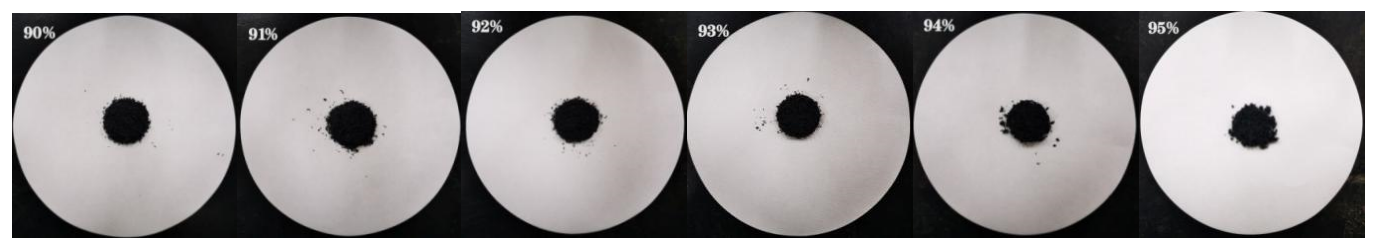

(a)

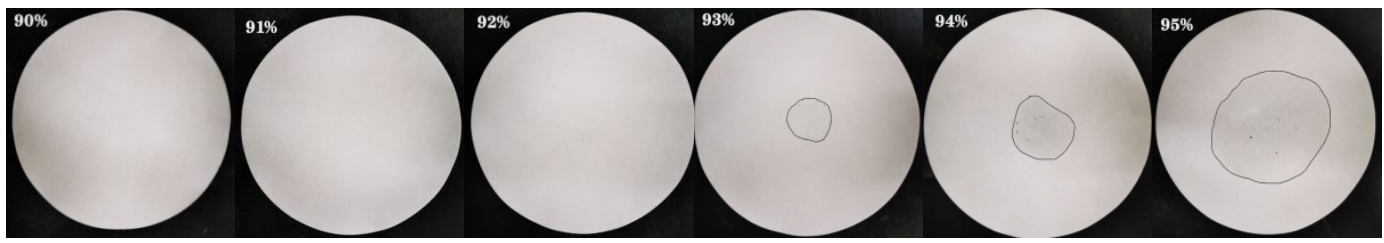

(b)
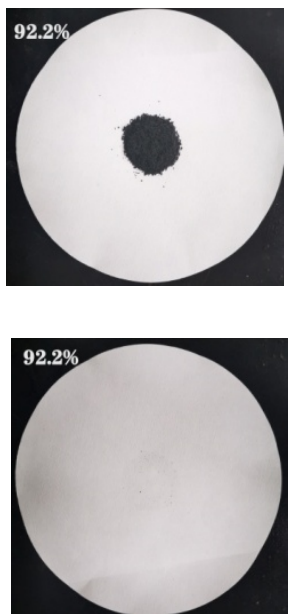

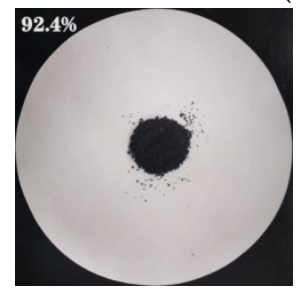

(c)

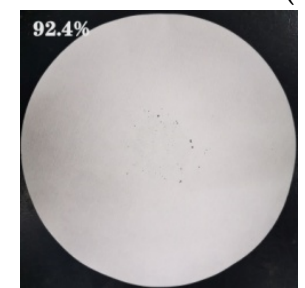

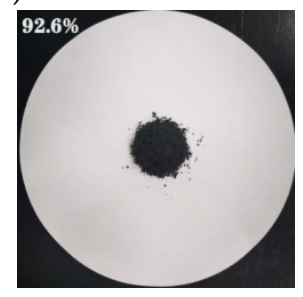

(c)

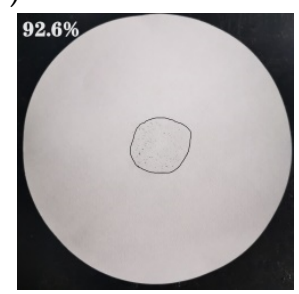

(d)
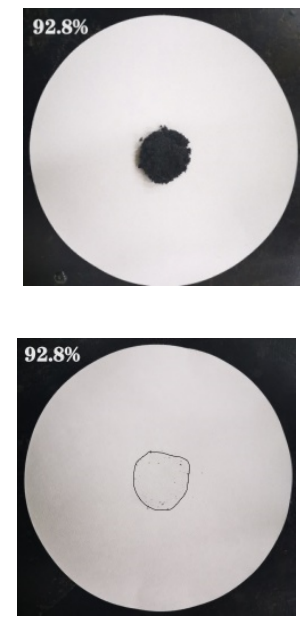

Figure 1. Photographs of CA-MA/EG samples before and after thermal treatments. (a) The first group of samples after thermal treatment, (b) the first group of filter papers with specimens brushed off after thermal treatment, (c) the second group of samples after thermal treatment, (d) the second group of filter papers with samples brushed off after thermal treatment.

To further fix the accurate mass ratio, $5 \mathrm{~g}$ CA-MA/EG composite phase change materials with four different ratios were weighed again for preparation, with mass ratios of $92.2 \%, 92.4 \%, 92.6 \%$, and $92.8 \%$. We repeated the same steps and observed the leakage of the sample. As shown in Figure 1c, there was no leakage of the CA-MA solution around the four samples, indicating that there was little difference. After the samples were brushed off (In Figure 1d), it was found that samples with a mass ratio of $92.2 \%$ and $92.4 \%$ were not adsorbed, while those with a mass ratio of $92.6 \%$ and $92.8 \%$ of the sample filter paper demonstrated slight leakage. In conclusion, it can be determined that the optimal ratio of CA-MA in CA-MA /EG was $92.4 \%$.

\subsection{Thermal Properties of the CPCMs}

The heat-storage properties of phase change composites can be measured by DSC and the effects are indicated in Table 2 and Figure 2. The phase transition temperature of the CA-MA eutectic mixture 
was $19.45^{\circ} \mathrm{C}$ and the latent heat of phase transition was $150.9 \mathrm{~J} / \mathrm{g}$. The phase transition temperature of the CA-MA/EG composite PCM was $19.78^{\circ} \mathrm{C}$, and the latent heat of phase transition was $137.3 \mathrm{~J} / \mathrm{g}$. It follows that the initial phase transition temperature of the endothermic curve of CA-MA/EG was slightly delayed compared with that of CA-MA, which occurred in previous studies $[34,37,39,40]$.

Table 2. Heat performances of CA-MA and CA-MA/EG.

\begin{tabular}{ccccccc}
\hline & \multicolumn{3}{c}{ Melting } & \multicolumn{3}{c}{ Freezing } \\
\cline { 2 - 7 } PCM & $\begin{array}{c}\text { Phase } \\
\text { Change } \\
\text { Temperature } \\
\left({ }^{\circ} \mathbf{C}\right)\end{array}$ & $\begin{array}{c}\text { Peak } \\
\text { Temperature } \\
\left({ }^{\circ} \mathbf{C}\right)\end{array}$ & $\begin{array}{c}\text { Phase } \\
\text { Change } \\
\text { Latent Heat } \\
\mathbf{( J / g )}\end{array}$ & $\begin{array}{c}\text { Phase } \\
\text { Change } \\
\text { Temperature } \\
\left({ }^{\circ} \mathbf{C}\right)\end{array}$ & $\begin{array}{c}\text { Peak } \\
\text { Temperature } \\
\left({ }^{\circ} \mathbf{C}\right)\end{array}$ & $\begin{array}{c}\text { Phase } \\
\text { Change } \\
\text { Latent Heat } \\
\mathbf{~ J / g )}\end{array}$ \\
\hline CA-MA & $19.45 \pm 0.05$ & $22.92 \pm 0.05$ & $150.9 \pm 0.2$ & $18.34 \pm 0.05$ & $16.45 \pm 0.05$ & $149.2 \pm 0.1$ \\
CA-MA/EG & $19.78 \pm 0.05$ & $24.15 \pm 0.05$ & $137.3 \pm 0.1$ & $18.85 \pm 0.05$ & $14.83 \pm 0.05$ & $139.8 \pm 0.1$ \\
\hline
\end{tabular}

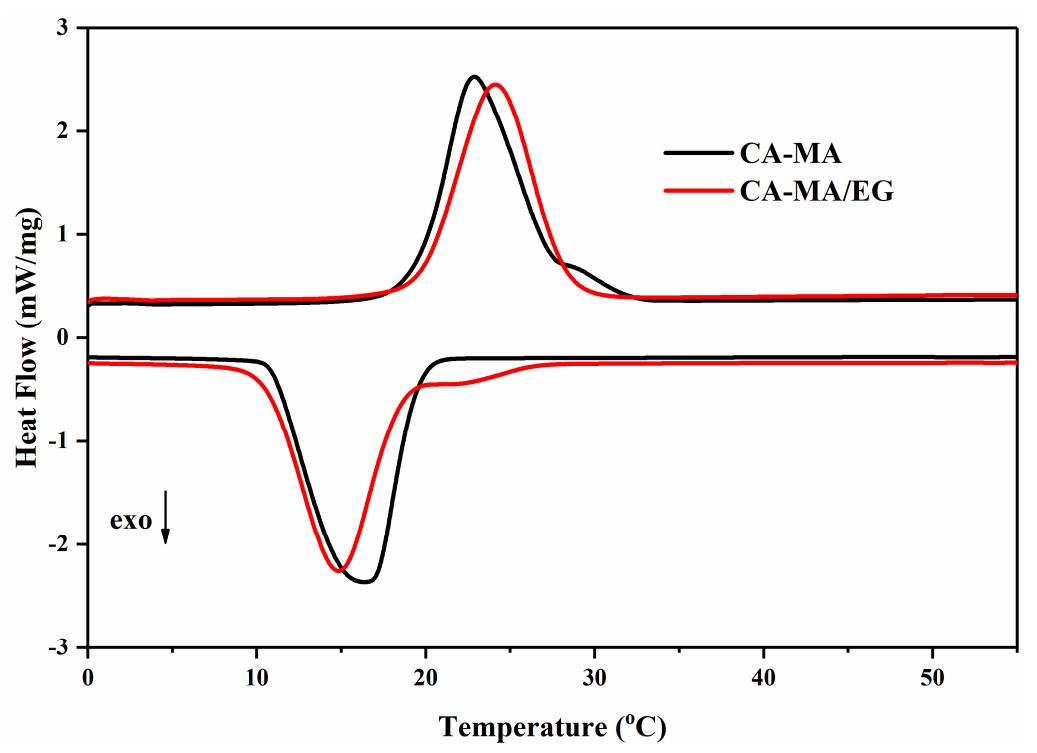

Figure 2. Differential scanning calorimetry (DSC) graphs of CA-MA and CA-MA/EG.

Three reasons for this phenomenon are probable. First, there is a weak interaction between fatty acids and EG pores, and EG has good thermal conductivity; therefore, the phase transition temperature of CPCM changes slightly. Secondly, there is an error in the instrument and experiment. Finally, the purity of the experimental materials is different. However, the shape and position of the two absorption peaks are basically the same, indicating that it has no new material produced in the preparation process of the composites. EG only plays a role with adsorbed material in composites and has little influence on the phase transition temperature and the latent heat of the composite PCM.

As shown in Table 2, there is a certain degree of undercooling for PCM and the undercooling decreases to a certain extent after recombination. Although EG can improve the thermal properties of PCM, there is no evidence that EG can reduce the undercooling of fatty acids. The change in supercooling may be caused by impurities. Impurities may be inserted in the preparation of EG and CPCM. Impurities have a strong influence on the dissolution and solidification of PCM. In some cases, impurities may also be a good nucleating agent, which can reduce the undercooling of PCM.

\subsection{Microstructure of EG and CA-MA/EG Composite PCMs}

The microscopic structure of the EG and CA-MA/EG composite PCMs was determined using SEM and the effects are indicated in Figure 3. Figure 3a shows that the EG has a large number of loose and folded porous structures, which have a strong adsorption capacity and can absorb the CA-MA 
eutectic melt mixture. The SEM diagram of CA-MA/EG (Figure 3b) indicates that, due to the high adsorption of the EG mesoporous structure, the eutectic mixture of CA-MA is adsorbed, and the pores are filled with solution and become full. The porous structure provides surface tension for the eutectic melt mixture, making the solution less leaky. Therefore, EG is a good adsorption material for CA-MA phase change materials, due to its superior adsorption performance, and as a base material, it can provide certain mechanical strengths and prevent the leakage of molten materials.

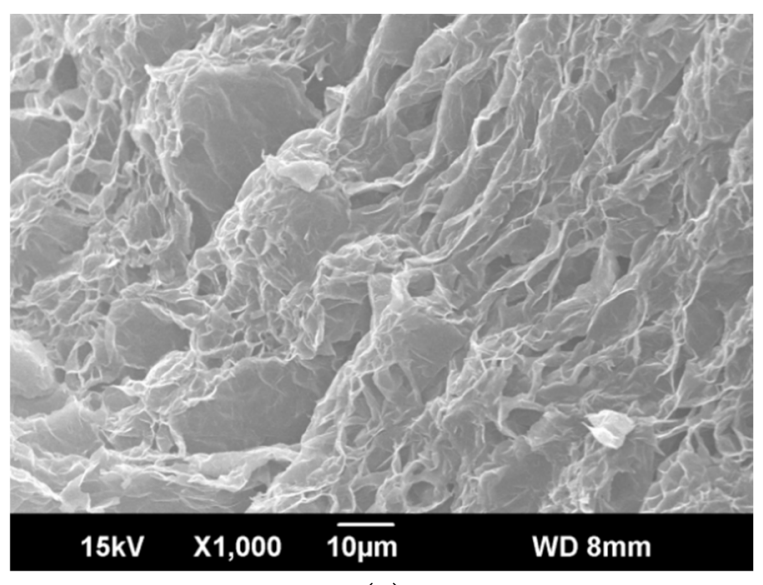

(a)

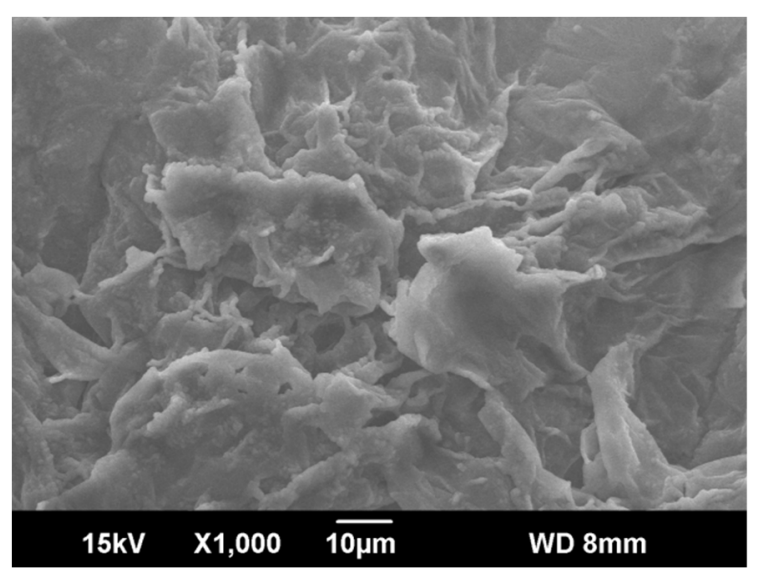

(b)

Figure 3. Microstructures of (a) EG and (b) CA-MA/EG.

\subsection{Improvement of the Thermal Performance of the CPCMs}

The high thermal conductivity of aliphatic acids as PCMs is one of the most important requirements. The thermal conductivity of a single aliphatic acid or polyfatty acid eutectic mixture is relatively poor; thus, it is necessary to add a substrate with better thermal conductivity to improve the thermal conductivity. EG has a good adsorption capacity and high thermal conductivity due to its porous properties. To test the thermal conductivity of PCMs, the heat storage and release experiment and the transient plane heat source technique were used.

In order to test the accuracy, the temperature probe was placed in the center of the CA-MA and CA-MA/EG phase change materials, and the two materials were placed in a stable temperature environment. A test began when the temperature of the material reached the set value and was stable. The temperature of the storage process was set at $48^{\circ} \mathrm{C}$, and that of the release process was set at $0{ }^{\circ} \mathrm{C}$. The test effects are indicated in Figure 4. Figure 4a shows the storage curves of the two materials. It can be clearly seen that the time taken for CA-MA/EG to reach the set point is faster than CA-MA. It takes $115 \mathrm{~min}$ at $48{ }^{\circ} \mathrm{C}$ for the CA-MA, while it takes only $63 \mathrm{~min}$ for the CA-MA/EG to be heated to $48^{\circ} \mathrm{C}$. Figure $4 \mathrm{~b}$ shows the release curves of the two materials. It takes $81 \mathrm{~min}$ for the CA-MA to complete the exothermic process, while it takes only $25 \mathrm{~min}$ for CA-MA/EG to complete the release process. The effects indicate that the thermal conductivity of CA-MA/EG is higher than that of CA-MA for the porous structure of EG.

Although EG can greatly ameliorate the thermal conductivity of CA-MA, EG is a porous structure with a loose texture, which determines its thermal conductivity concerning the packing density of composite PCMs. When the packing density is higher, the thermal conductivity is also higher. To ascertain the relationship between the thermal conductivity of CA-MA/EG with different packing densities, the thermal conductivity of several composite phase change energy storage materials with different packing densities was measured. As shown in Table 3 and Figure 5, the packing densities of PCM were $764.25,625.08,910.02,850.80$, and $604.41 \mathrm{~kg} / \mathrm{m}^{3}$, and the thermal conductivities were $1.725,1.594,2.168,1.958$, and $1.458 \mathrm{~W} / \mathrm{m} \cdot \mathrm{K}$. Through fitting analysis, the thermal conductivity of CA-MA/EG had a linear relationship with the bulk density. The fitting formula is $y=-0.27542+$ $0.00205 x\left(R^{2}=0.92455\right)$. 


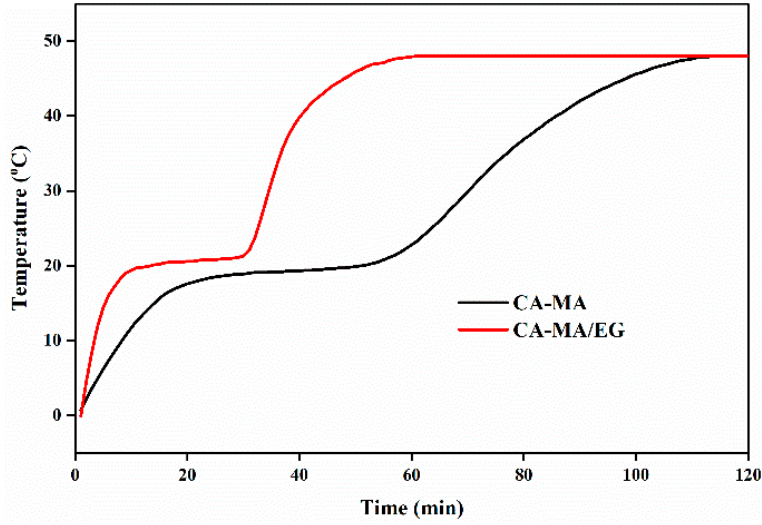

(a)

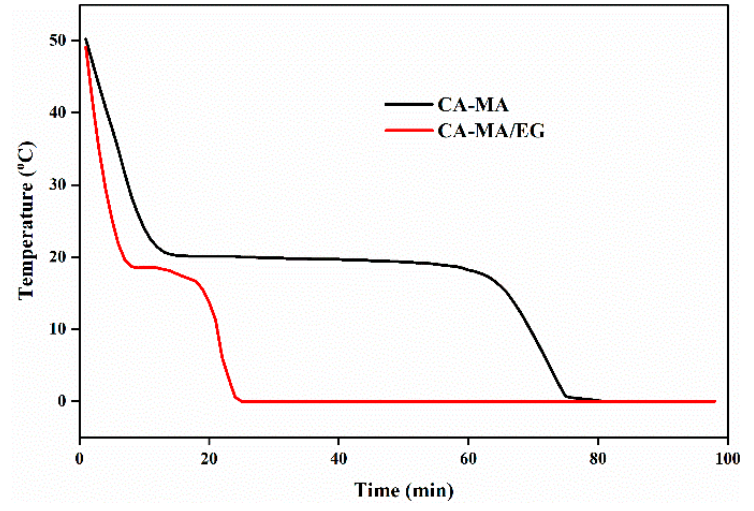

(b)

Figure 4. Melting (a) and freezing (b) graphs of CA-MA and CA-MA/EG.

Table 3. Parameters of CA-MA/EG with different packing densities.

\begin{tabular}{cccccc}
\hline & Mass (g) & $\begin{array}{c}\text { Thickness } \\
\mathbf{( m m})\end{array}$ & $\begin{array}{c}\text { Diameter } \\
\mathbf{( m m )}\end{array}$ & $\begin{array}{c}\text { Density } \\
\mathbf{( k g} / \mathbf{m} 3)\end{array}$ & $\begin{array}{c}\text { Thermal Conductivity } \\
\mathbf{( W / m} \cdot \mathbf{K})\end{array}$ \\
\cline { 2 - 6 } PCM & 1.6654 & 3.92 & 29.92 & $604.42 \pm 0.03$ & $1.46 \pm 0.04$ \\
& 1.4601 & 3.33 & 29.88 & $625.26 \pm 0.03$ & $1.59 \pm 0.05$ \\
& 2.1612 & 4.01 & 29.96 & $764.75 \pm 0.03$ & $1.73 \pm 0.05$ \\
& 2.2549 & 4.22 & 28.28 & $850.90 \pm 0.02$ & $1.96 \pm 0.06$ \\
& 2.0588 & 3.23 & 29.86 & $910.65 \pm 0.02$ & $2.17 \pm 0.07$ \\
\hline
\end{tabular}

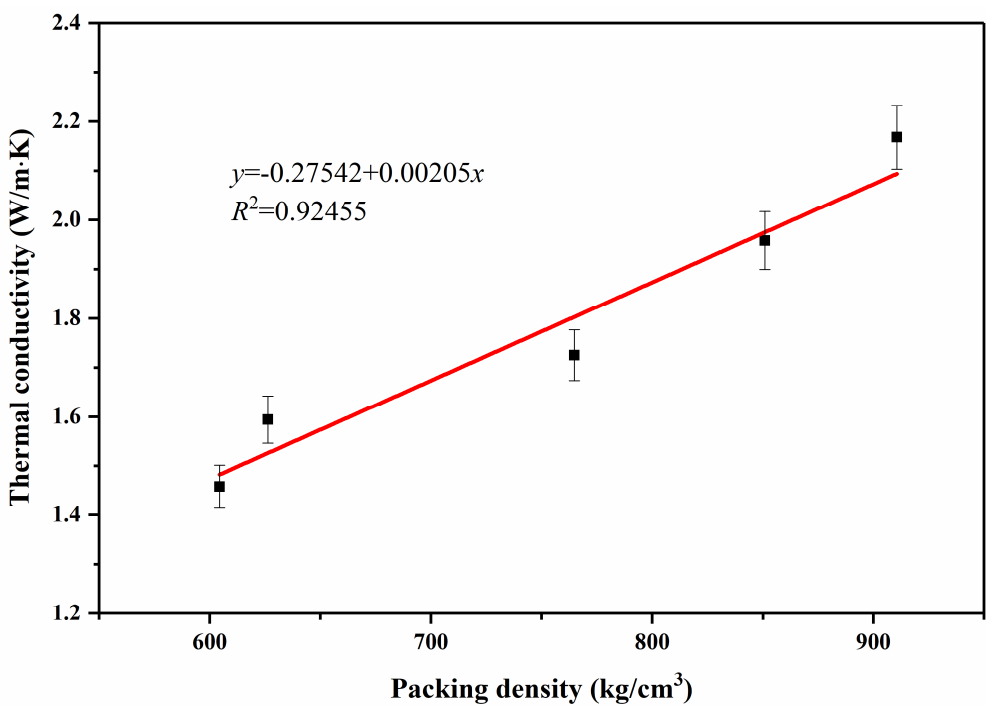

Figure 5. CA-MA/EG thermal conductivity variations with the packing density.

\subsection{Thermo-Stability and Thermo-Reliability of the CPCMs}

A PCM must be sufficiently stable and cannot be volatile during multiple repeated exothermic phase changes. The thermostability of CA-MA/EG was tested using thermogravimetric analysis. The TGA curves are shown in Figure 6. The CA-MA /EG began to lose weight at approximately $140^{\circ} \mathrm{C}$. After the first derivative of the TG curve, the maximum weight loss rate of the CA-MA/EG was obtained at $194.4^{\circ} \mathrm{C}$. Finally, it evaporated completely at approximately $230{ }^{\circ} \mathrm{C}$.

The thermophysical properties of a good phase change material should not change much after many phase change cycles. To determine the thermophysiological properties of CA-MA/EG after many phase transition thermal cycles, the DSC test was conducted again on the material after 500 and 1000 cycles of CA-MA/EG. The test results are shown in Table 4 and Figure 7 . Through comparison of 
the curves, the peak shape of the DSC curve of CA-MA/EG after multiple cycles was almost exactly the same, indicating that the phase transition temperature and the latent heat before and after the cycle were not changed much. After analyzing the data, we found that after 500 and 1000 cycles, the phase transition temperature of CA-MA/EG changed by $0.1{ }^{\circ} \mathrm{C}$ and $0.3^{\circ} \mathrm{C}$, respectively, the latent heat of phase transition decreased by $2.03 \%$ and $10.6 \%$, respectively, and the change values were relatively small. This demonstrates that CA-MA/EG composite phase change materials show great thermal reliability.

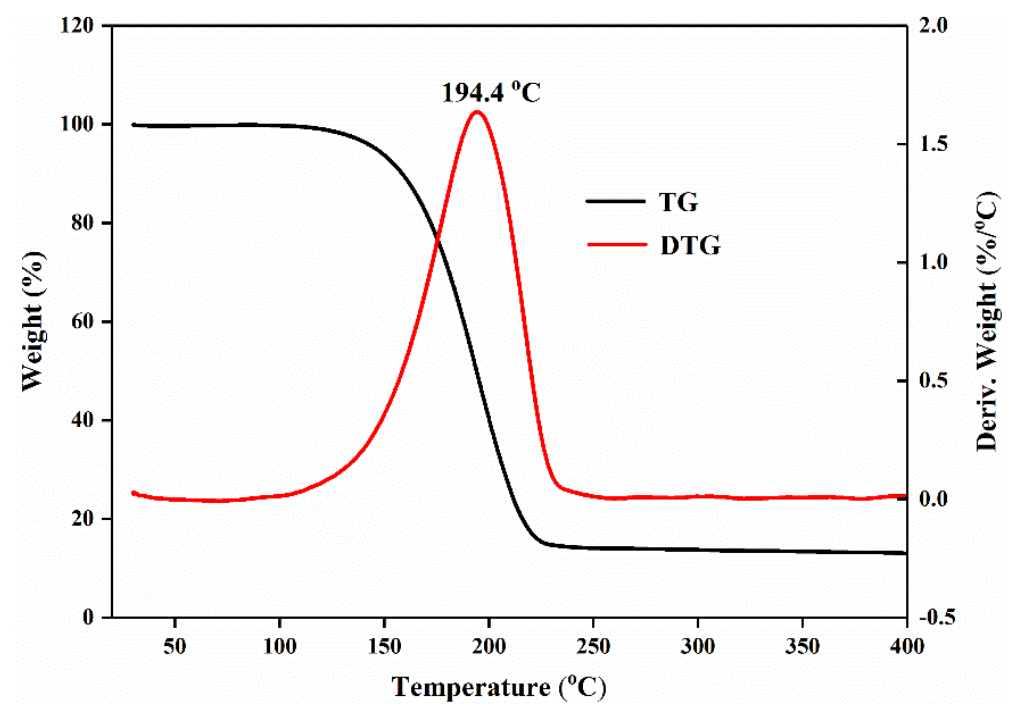

Figure 6. The CA-MA/EG thermal conductivity variations with the packing density.

Table 4. Heat performances of CA-MA and CA-MA/EG.

\begin{tabular}{ccccc}
\hline \multirow{2}{*}{$\begin{array}{c}\text { Number of } \\
\text { Thermal Cycling }\end{array}$} & \multicolumn{2}{c}{ Melting } & \multicolumn{2}{c}{ Freezing } \\
\cline { 2 - 5 } & $\begin{array}{c}\text { Phase Change } \\
\text { Temperature }\left({ }^{\circ} \mathrm{C}\right)\end{array}$ & $\begin{array}{c}\text { Phase Change } \\
\text { Latent Heat }(\mathrm{J} / \mathrm{g})\end{array}$ & $\begin{array}{c}\text { Phase Change } \\
\text { Temperature }\left({ }^{\circ} \mathrm{C}\right)\end{array}$ & $\begin{array}{c}\text { Phase Change } \\
\text { Latent Heat }(\mathrm{J} / \mathrm{g})\end{array}$ \\
\hline 0 & $19.78 \pm 0.05$ & $137.3 \pm 0.1$ & $18.85 \pm 0.05$ & $139.8 \pm 0.1$ \\
500 & $19.62 \pm 0.05$ & $134.5 \pm 0.1$ & $18.73 \pm 0.05$ & $138.1 \pm 0.1$ \\
1000 & $19.42 \pm 0.05$ & $134.5 \pm 0.1$ & $18.64 \pm 0.05$ & $128.7 \pm 0.1$ \\
\hline
\end{tabular}

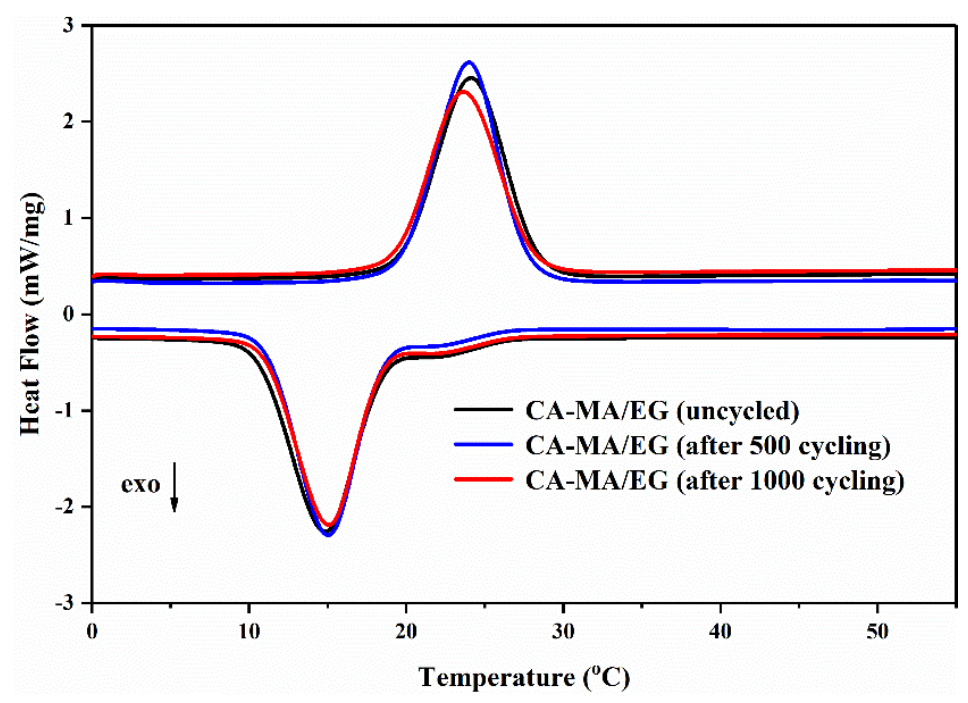

Figure 7. DSC graphs of CA-MA/EG CPCMs before and after thermal cycling. 


\section{Conclusions}

The form-stable CA-MA/EG CPCMs with the largest CA-MA quality content of $92.4 \%$ is suitable for latent heat thermal energy storage (LHTES) systems, such as backfill materials of soil-source heat pump systems. The SEM characterization shows that CA-MA can equably disperse in the network structure of EG, and no seepage of liquid CA-MA was found. The DSC effects indicated that the CPCMs had appropriate phase change temperatures $\left(T_{m}: 19.78^{\circ} \mathrm{C}, T_{f}: 18.85^{\circ} \mathrm{C}\right)$ and high latent heat $\left(H_{m}: 137.3 \mathrm{~J} / \mathrm{g}, H_{f}: 139.9 \mathrm{~J} / \mathrm{g}\right)$. By the thermal storage/release experiment, we concluded that adding the EG into CA-MA led to a notable advancement in thermal conductivity. The TGA test proved that the CA-MA/EG CPCMs had excellent stability within the operating temperature range. The thermal cycling test results after 1000 thermal cycles showed that the CA-MA/EG CPCMs had positive thermal reliability. Consequently, the prepared CA-MA/EG composite PCM can only be utilized in low-temperature LHTES systems, for instance, as backfill materials of ground-source heat-pump systems.

Author Contributions: Conceptualization, D.Z. and Y.L.; methodology, D.Z.; validation, D.Z. and Y.Z.; formal analysis, D.Z. and Y.Z.; data curation, D.Z. and Y.Z.; writing-original draft preparation, D.Z. and J.Y.; writing-review and editing, D.Z. and J.Y.; funding acquisition, D.Z. and Y.L. All authors have read and agreed to the published version of the manuscript.

Funding: This research was funded by the Natural Science Foundation of Hunan Provincial (Grant NO. 2018JJ2366), the Education Department Foundation of Hunan Provincial (Grant NO. 18K097), the National Natural Science Foundation of China (Grant NO. 51776226) and the Key R and D Project of Hunan Provincial (Grant NO. 2018GK2074).

Conflicts of Interest: The authors declare no conflict of interest.

\section{References}

1. $\quad$ Akeiber, H.; Nejat, P.; Majid, M.Z.A.; Wahid, M.A.; Jomehzadeh, F.; Zeynali Famileh, I.; Calautit, J.K.; Hughes, B.R.; Zaki, S.A. A Review on Phase Change Material (PCM) for Sustainable Passive Cooling in Building Envelopes. Renew. Sustain. Energy Rev. 2016, 60, 1470-1497. [CrossRef]

2. Mofijur, M.; Mahlia, T.M.I.; Silitonga, A.S.; Ong, H.C.; Silakhori, M.; Hasan, M.H.; Putra, N.; Rahman, S.M. Phase Change Materials (PCM) for Solar Energy Usages and Storage: An Overview. Energies 2019, 12, 3167. [CrossRef]

3. He, H.; Zhao, P.; Yue, Q.; Gao, B.; Yue, D.; Li, Q. A Novel Polynary Fatty Acid/Sludge Ceramsite Composite Phase Change Materials and Its Applications in Building Energy Conservation. Renew. Energy 2015, 76, 45-52. [CrossRef]

4. Pereira da Cunha, J.; Eames, P. Thermal Energy Storage for Low and Medium Temperature Applications Using Phase Change Materials-A Review. Appl. Energy 2016, 177, 227-238. [CrossRef]

5. Zou, T.; Fu, W.; Liang, X.; Wang, S.; Gao, X.; Zhang, Z.; Fang, Y. Preparation and Performance of Modified Calcium Chloride Hexahydrate Composite Phase Change Material for Air-Conditioning Cold Storage. Int. J. Refrig. 2018, 95, 175-181. [CrossRef]

6. Kenisarin, M.M. Thermophysical Properties of Some Organic Phase Change Materials for Latent Heat Storage. A Review. Sol. Energy 2014, 107, 553-575. [CrossRef]

7. Mohamed, S.A.; Al-Sulaiman, F.A.; Ibrahim, N.I.; Zahir, M.H.; Al-Ahmed, A.; Saidur, R.; Yılbaş, B.S.; Sahin, A.Z. A Review on Current Status and Challenges of Inorganic Phase Change Materials for Thermal Energy Storage Systems. Renew. Sustain. Energy Rev. 2017, 70, 1072-1089. [CrossRef]

8. Zhang, P.; Xiao, X.; Ma, Z.W. A Review of the Composite Phase Change Materials: Fabrication, Characterization, Mathematical Modeling and Application to Performance Enhancement. Appl. Energy 2016, 165, 472-510. [CrossRef]

9. Şahan, N.; Fois, M.; Paksoy, H. Improving Thermal Conductivity Phase Change Materials-A Study of Paraffin Nanomagnetite Composites. Sol. Energy Mater. Sol. Cells 2015, 137, 61-67. [CrossRef]

10. Yuan, Y.; Zhang, N.; Tao, W.; Cao, X.; He, Y. Fatty Acids as Phase Change Materials: A Review. Renew. Sustain. Energy Rev. 2014, 29, 482-498. [CrossRef] 
11. Sarı, A.; Karaipekli, A. Preparation, Thermal Properties and Thermal Reliability of Palmitic Acid/Expanded Graphite Composite as Form-Stable PCM for Thermal Energy Storage. Sol. Energy Mater. Sol. Cells 2009, 93, 571-576. [CrossRef]

12. Kahwaji, S.; White, M.A. Prediction of the Properties of Eutectic Fatty Acid Phase Change Materials. Thermochim. Acta 2018, 660, 94-100. [CrossRef]

13. Zhao, P.; Yue, Q.; He, H.; Gao, B.; Wang, Y.; Li, Q. Study on Phase Diagram of Fatty Acids Mixtures to Determine Eutectic Temperatures and the Corresponding Mixing Proportions. Appl. Energy 2014, 115, 483-490. [CrossRef]

14. Ke, H. Phase Diagrams, Eutectic Mass Ratios and Thermal Energy Storage Properties of Multiple Fatty Acid Eutectics as Novel Solid-Liquid Phase Change Materials for Storage and Retrieval of Thermal Energy. Appl. Therm. Eng. 2017, 113, 1319-1331. [CrossRef]

15. Paul, A.; Shi, L.; Bielawski, C.W. A Eutectic Mixture of Galactitol and Mannitol as a Phase Change Material for Latent Heat Storage. Energy Convers. Manag. 2015, 103, 139-146. [CrossRef]

16. Diarce, G.; Gandarias, I.; Campos-Celador, Á.; García-Romero, A.; Griesser, U.J. Eutectic Mixtures of Sugar Alcohols for Thermal Energy Storage in the 50-90 ${ }^{\circ} \mathrm{C}$ Temperature Range. Sol. Energy Mater. Sol. Cells 2015, 134, 215-226. [CrossRef]

17. Han, L.; Ma, G.; Xie, S.; Sun, J.; Jia, Y.; Jing, Y. Thermal Properties and Stabilities of the Eutectic Mixture: 1,6-Hexanediol/Lauric Acid as a Phase Change Material for Thermal Energy Storage. Appl. Therm. Eng. 2017, 116, 153-159. [CrossRef]

18. Gunasekara, S.N.; Martin, V.; Chiu, J.N. Phase Equilibrium in the Design of Phase Change Materials for Thermal Energy Storage: State-of-the-Art. Renew. Sustain. Energy Rev. 2017, 73, 558-581. [CrossRef]

19. Saeed, R.M.; Schlegel, J.P.; Castano, C.; Sawafta, R.; Kuturu, V. Preparation and Thermal Performance of Methyl Palmitate and Lauric Acid Eutectic Mixture as Phase Change Material (PCM). J. Energy Storage 2017, 13, 418-424. [CrossRef]

20. Fan, L.; Khodadadi, J.M. Thermal Conductivity Enhancement of Phase Change Materials for Thermal Energy Storage: A Review. Renew. Sustain. Energy Rev. 2011, 15, 24-46. [CrossRef]

21. Wu, S.; Yan, T.; Kuai, Z.; Pan, W. Thermal Conductivity Enhancement on Phase Change Materials for Thermal Energy Storage: A Review. Energy Storage Mater. 2020, 25, 251-295. [CrossRef]

22. Xu, T.; Chen, Q.; Huang, G.; Zhang, Z.; Gao, X.; Lu, S. Preparation and Thermal Energy Storage Properties of D-Mannitol/Expanded Graphite Composite Phase Change Material. Sol. Energy Mater. Sol. Cells 2016, 155, 141-146. [CrossRef]

23. Karaipekli, A.; Sarı, A.; Kaygusuz, K. Thermal Conductivity Improvement of Stearic Acid Using Expanded Graphite and Carbon Fiber for Energy Storage Applications. Renew. Energy 2007, 32, 2201-2210. [CrossRef]

24. Ramakrishnan, S.; Sanjayan, J.; Wang, X.; Alam, M.; Wilson, J. A Novel Paraffin/Expanded Perlite Composite Phase Change Material for Prevention of PCM Leakage in Cementitious Composites. Appl. Energy 2015, 157, 85-94. [CrossRef]

25. Tang, F.; Su, D.; Tang, Y.; Fang, G. Synthesis and Thermal Properties of Fatty Acid Eutectics and Diatomite Composites as Shape-Stabilized Phase Change Materials with Enhanced Thermal Conductivity. Sol. Energy Mater. Sol. Cells 2015, 141, 218-224. [CrossRef]

26. Wang, T.; Wang, S.; Luo, R.; Zhu, C.; Akiyama, T.; Zhang, Z. Microencapsulation of Phase Change Materials with Binary Cores and Calcium Carbonate Shell for Thermal Energy Storage. Appl. Energy 2016, 171, 113-119. [CrossRef]

27. Wu, Y.; Wang, T. Preparation and Characterization of Hydrated Salts/Silica Composite as Shape-Stabilized Phase Change Material via Sol-Gel Process. Thermochim. Acta 2014, 591, 10-15. [CrossRef]

28. Fu, X.; Liu, Z.; Wu, B.; Wang, J.; Lei, J. Preparation and Thermal Properties of Stearic Acid/Diatomite Composites as Form-Stable Phase Change Materials for Thermal Energy Storage via Direct Impregnation Method. J. Therm. Anal. Calorim. 2016, 123, 1173-1181. [CrossRef]

29. He, Y.; Zhang, X.; Zhang, Y.; Song, Q.; Liao, X. Utilization of Lauric Acid-Myristic Acid/Expanded Graphite Phase Change Materials to Improve Thermal Properties of Cement Mortar. Energy Build. 2016, 133, 547-558. [CrossRef]

30. Wei, H.; Xie, X.; Li, X.; Lin, X. Preparation and Characterization of Capric-Myristic-Stearic Acid Eutectic Mixture/Modified Expanded Vermiculite Composite as a Form-Stable Phase Change Material. Appl. Energy 2016, 178, 616-623. [CrossRef] 
31. Wu, S.; Li, T.X.; Yan, T.; Dai, Y.J.; Wang, R.Z. High Performance Form-Stable Expanded Graphite/Stearic Acid Composite Phase Change Material for Modular Thermal Energy Storage. Int. J. Heat Mass Transf. 2016, 102, 733-744. [CrossRef]

32. Lin, Y.; Jia, Y.; Alva, G.; Fang, G. Review on Thermal Conductivity Enhancement, Thermal Properties and Applications of Phase Change Materials in Thermal Energy Storage. Renew. Sustain. Energy Rev. 2018, 82, 2730-2742. [CrossRef]

33. Bose, P.; Amirtham, V.A. A Review on Thermal Conductivity Enhancement of Paraffinwax as Latent Heat Energy Storage Material. Renew. Sustain. Energy Rev. 2016, 65, 81-100. [CrossRef]

34. Zhou, D.; Zhou, Y.; Yuan, J.; Liu, Y. Palmitic Acid-Stearic Acid/Expanded Graphite as Form-Stable Composite Phase-Change Material for Latent Heat Thermal Energy Storage. J. Nanomater. 2020, 2020, 1-9. [CrossRef]

35. Yang, X.; Yuan, Y.; Zhang, N.; Cao, X.; Liu, C. Preparation and Properties of Myristic-Palmitic-Stearic Acid/Expanded Graphite Composites as Phase Change Materials for Energy Storage. Sol. Energy 2014, 99, 259-266. [CrossRef]

36. Liu, C.; Yuan, Y.; Zhang, N.; Cao, X.; Yang, X. A Novel PCM of Lauric-Myristic-Stearic Acid/Expanded Graphite Composite for Thermal Energy Storage. Mater. Lett. 2014, 120, 43-46. [CrossRef]

37. Zhang, H.; Gao, X.; Chen, C.; Xu, T.; Fang, Y.; Zhang, Z. A Capric-Palmitic-Stearic Acid Ternary Eutectic Mixture/Expanded Graphite Composite Phase Change Material for Thermal Energy Storage. Compos. Part A Appl. Sci. Manuf. 2016, 87, 138-145. [CrossRef]

38. Zhu, H.; Zhang, P.; Meng, Z.; Li, M. Thermal Characterization of Lauric-Stearic Acid/Expanded Graphite Eutectic Mixture as Phase Change Materials. J. Nanosci. Nanotechnol. 2015, 15, 3288-3294. [CrossRef]

39. Zhang, N.; Yuan, Y.; Wang, X.; Cao, X.; Yang, X.; Hu, S. Preparation and Characterization of Lauric-Myristic-Palmitic Acid Ternary Eutectic Mixtures/Expanded Graphite Composite Phase Change Material for Thermal Energy Storage. Chem. Eng. J. 2013, 231, 214-219. [CrossRef]

40. Ma, F.; Li, Y.; Cheng, L.; Chen, M. Preparation and properties of octadecane-palmitic acid/expanded graphite phase change energy storage materials. J. Aeronaut. Mater. 2010, 30, 66-69. [CrossRef]

41. Zhou, D.; Shi, C.; Yuan, W. Research on the Applicability of Solar Energy-Ground Source Heat Pump in Different Regions of China. In Proceedings of the 2011 Second International Conference on Digital Manufacturing \& Automation, Zhangjiajie, China, 5-7 August 2011; pp. 1026-1029. [CrossRef]

42. Zhou, D.; Zhou, Y.; Liu, Y.; Luo, X.; Yuan, J. Preparation and Performance of Capric-Myristic Acid Binary Eutectic Mixtures for Latent Heat Thermal Energy Storages. J. Nanomater. 2019, 2019, 1-9. [CrossRef] 